\title{
LA LEY ORGÁNICA DE COMUNICACIÓN DE ECUADOR, ¿UN AVANCE EN EL EJERCICIO EFECTIVO DE LAS LIBERTADES EXPRESIÓN E INFORMACIÓN Y EN LA PARTICIPACIÓN CIUDADANA?
}

ANTONIO MAGDALENO ALEGRÍA 
SUMARIO

INTRODUCCIÓN. 1. EL RECONOCIMIENTO CONSTITUCIONAL ECUATORIANO E INTERAMERICANO DE LAS LIBERTADES DE EXPRESIÓN E INFORMACIÓN. 2. LA VISIÓN DEMOCRÁTICA DE LAS LIBERTADES DE EXPRESIÓN E INFORMACIÓN COMO PREMISA DE LA LEY ORGÁNICA DE COMUNICACIÓN. 3. ESTUDIO DE LOS ASPECTOS MÁS CONTROVERTIDOS DE LA LEY ORGÁNICA DE COMUNICACIÓN. 3.1 La discutible calificación como servicio público de la actividad de los medios de comunicación. 3.2 La inapropiada utilización del concepto de censura previa y la obligatoriedad de informar sobre asuntos de interés público. 3.3 La obligación de elaborar códigos deontológicos. 3.4 El linchamiento mediático. 3.5 Las autoridades independientes de desarrollo normativo y control. 4. ¿SE PUEDEN CONSEGUIR IDÉNTICOS OBJETIVOS MEDIANTE OTROS MEDIOS MENOS RESTRICTIVOS? 


\title{
LA LEY ORGÁNICA DE COMUNICACIÓN DE ECUADOR, ¿UN AVANCE EN EL EJERCICIO EFECTIVO DE LAS LIBERTADES EXPRESIÓN E INFORMACIÓN Y EN LA PARTICIPACIÓN CIUDADANA?
}

\author{
ANTONIO MAGDALENO ALEGRÍA* \\ Profesor Contratado Doctor \\ Universidad de Cantabria
}

\section{INTRODUCCIÓN}

La Constitución de Ecuador de 2008, que se puede ubicar dentro de lo que se ha calificado como neoconstitucionalismo latinoamericano ${ }^{1}$, incluye un importante número de instituciones innovadoras. En materia de derechos y libertades contiene una amplísima tabla, que comprende desde las libertades públicas clásicas hasta el reconocimiento de derechos a la naturaleza. En referencia a las libertades de comunicación, los arts. 66.6 y 18 de la Constitución reconocen, respectivamente, las libertades de expresión y de información, derechos considerados esenciales para garantizar el denominado buen vivir o sumak kaw-

* Departamento de Derecho Público. Área de Derecho Constitucional. Facultad de Derecho. Universidad de Cantabria. Avda. de los Castros, s/n. 39005 Santander. Email: antonio.magdaleno@unican.es

${ }^{1}$ Sobre el neoconstitucionalismo latinoamericano, a modo de ejemplo, véase ÁviLA SANTAMARÍA, R. (2011). El neoconstitucionalismo transformador, el Estado y el Derecho en la Constitución de 2008, Quito, Abya Yala-UASB, págs. 59 y ss. 
say. Dada su importancia para el sistema democrático, el art. 384 de la Constitución prescribe que el sistema de comunicación social asegurará el ejercicio de los derechos de la comunicación, la información y la libertad de expresión, y fortalecerá la participación ciudadana.

En desarrollo de los citados preceptos constitucionales, el legislador ecuatoriano aprobó la Ley Orgánica de Comunicación (en adelante, LOC) cuyo ámbito de aplicación comprende todo tipo de información u opinión que se produzca, reciba o difunda e intercambie a través de los medios de comunicación social ${ }^{2}$. La norma pretende subsanar la situación precedente del país donde, casi en exclusiva, grupos con importantes intereses políticos y financieros (singularmente entidades bancarias) disfrutaban de las libertades de comunicación pública, debido a que podían asumir los importantes costes que implican los medios de comunicación de masas ${ }^{3}$. En otras palabras, se trata de una norma que, en principio, pretende fomentar el ejercicio pleno y eficaz de las libertades de comunicación por parte de todos los ciudadanos y de los grupos en los que se integran, así como garantizar el derecho a recibir información de relevancia pública, con el objetivo último de asegurar la participación de los ciudadanos en el sistema democrático. A tal efecto, la LOC establece que los medios de comunicación (independientemente de su titularidad pública, privada o comunitaria) prestan

2 Art. 3 LOC. Por el contrario, según el art. 2 LOC quedan excluidos del ámbito de aplicación de la norma las opiniones e informaciones que de modo personal se emitan a través de internet.

3 Durante las últimas décadas, los medios de comunicación han estado vinculados a las élites $\mathrm{y}$, singularmente, a las entidades financieras ecuatorianas. Tras la crisis bancaria y la quiebra de diversas entidades financieras, diferentes medios de comunicación fueron asumidos por el Estado. De hecho, esta circunstancia permitió al Presidente Correa crear un importante y hasta ese momento inexistente sector público de medios de comunicación compuesto por prensa escrita, radio, televisión y agencia de noticias.

Con el objeto de evitar el control de los medios de comunicación privados por parte de las entidades financieras y, en definitiva, la excesiva concentración de los medios, el art. 312 de la Constitución establece que «las entidades o grupos financieros no podrán poseer participaciones permanentes, totales o parciales en empresas ajenas a la actividad financiera. Se prohíbe la participación en el control del capital, la inversión o el patrimonio de los medios de comunicación social, a entidades o grupos financieros, sus representantes legales, miembros de su directorio y accionistas». La disposición transitoria vigesimonovena de la Constitución estableció que las participaciones accionarias que posean las personas jurídicas del sector financiero en empresas ajenas a este sector se enajenarán en el plazo de dos años a partir de la vigencia de la Constitución.

Sobre la cuestión, véase CHeCa Godoy, A. (2011). «La batalla política y legal en Ecuador ante la creación de un sector estatal de medios de comunicación», Anuario americanista Europeo, núm. 9, págs. 42 y ss., y (2012). «La Banca y la propiedad de los medios: el caso de Ecuador», Revista Latina de Comunicación social, núm. 67, págs. 125 y ss. Con carácter general, sobre las medidas para evitar la concentración de medios de comunicación, véase GómEZ, A. (2002). El control de las concentraciones de medios de comunicación. Derecho español y comparado, Madrid, Dykinson. 
un servicio público y, por ello, impone una serie de deberes como, por ejemplo, la obligación de cubrir y difundir los hechos de interés público ${ }^{4}$, la necesidad de elaborar códigos deontológicos con determinados contenidos, etc.

A pesar del gran respaldo parlamentario y el reciente aval de la Corte Constitucional $^{5}$, la LOC continúa provocando un importante rechazo en diversos sectores. Así, han manifestado su disconformidad, con diferentes argumentos, la mayoría de los medios de comunicación privados del país, las asociaciones y organizaciones de periodistas nacionales e internacionales ${ }^{6}$ o la Relatoría especial para la libertad de expresión de la Comisión Interamericana de Derechos Humanos ${ }^{7}$.

El presente estudio analizará si la LOC supone una auténtica democratización del ejercicio de las libertades de expresión e información, lo que supone un fortalecimiento de la participación ciudadana o si, por el contrario, contiene algunas regulaciones que hacen dudar de la claridad de esta intención, pues pueden permitir a los poderes públicos influir en los contenidos comunicativos de los mass media. Para comprobar la legitimidad de la norma, se acudirá a la Constitución de Ecuador y, por remisión de ésta, a los estándares internacionales sobre libertades de expresión y de información, en especial a la Convención americana sobre Derechos Humanos y a los criterios usualmente aceptados en derecho comparado ${ }^{8}$.

${ }^{4}$ En el momento de la redacción del presente texto, el Gobierno de Ecuador ha anunciado su intención de plantear una enmienda a la Constitución de 2008 con el objeto de que el Texto fundamental califique expresamente la comunicación social como un servicio público.

${ }^{5}$ Con la excepción de un escaso número de preceptos, la Sentencia de la Corte Constitucional de Ecuador núm. 003-14-SIN-CC, de 14 de septiembre de 2014, ha confirmado la constitucionalidad de la LOC.

${ }^{6}$ A modo de ejemplo, Reporteros sin fronteras considera que el país se encuentra en una situación de polarización extrema entre el gobierno de Rafael Correa y algunos medios de comunicación privados. En este sentido, ha denunciado muchos casos de excesos del Gobierno, pero también algunos cometidos por los medios privados. Véase el informe Periodistas ecuatorianos bajo presión, un año después de la ley de comunicación, que puede ser consultado a través del siguiente enlace: http://rsf.org/supercom/es.html (fecha de consulta: 5/3/2015). Asimismo, véase CaÑIZALES, A. (2014). «Libertad de prensa y expresión en los países andinos. Tensión, amenazas y restricciones», Temas de Comunicación, núm. 29, págs. 61 y ss.

7 Concretamente, la Relatoría especial para la libertad de expresión envió una carta a las autoridades ecuatorianas donde se manifiestan serias reticencias sobre importantes aspectos de la LOC. La citada carta puede consultarse en el siguiente enlace: http://www.oas.org/es/cidh/ expresion/docs/2013_06_28_carta_ecuador\%28vp\%29_espanol.pdf

$8 \mathrm{Al}$ respecto, téngase en cuenta que si bien el segundo párrafo del artículo 384 de la Constitución establece un mandato dirigido a los poderes públicos para que formulen una política pública de comunicación, posteriormente recuerda que lo deberán cumplir «con respeto irrestricto de la libertad de expresión y de los derechos de la comunicación consagrados en la Constitución y los instrumentos internacionales de derechos humanos». 


\section{EL RECONOCIMIENTO CONSTITUCIONAL ECUATORIANO E INTERAMERICANO DE LAS LIBERTADES DE EXPRESIÓN E INFORMACIÓN}

La Constitución ecuatoriana de 2008 reconoce los derechos a la comunicación de una manera sumamente extensa, dispersa y, a veces, confusa. Así, el art. 16 reconoce que todas las personas, de forma individual o colectiva, tienen derecho a: «una comunicación libre, intercultural, incluyente, diversa y participativa (...)». Los arts. 18.1 y 66.6 reconocen, respectivamente, la libertad de «buscar, recibir, intercambiar, producir y difundir información veraz» y «el derecho a opinar y expresar su pensamiento libremente y en todas sus formas y manifestaciones». Otros preceptos de la Constitución establecen números mandatos dirigidos a los poderes públicos. Así, por ejemplo, el art. 17 establece que el Estado fomentará la pluralidad y la diversidad en la comunicación, el art. 19 establece que «la ley regulará la prevalencia de contenidos con fines informativos, educativos y culturales en la programación de los medios de comunicación (...)» o el art. 20 prescribe que «el Estado garantizará la cláusula de conciencia a toda persona, y el secreto profesional y la reserva de la fuente a quienes informen, emitan sus opiniones a través de los medios u otras formas de comunicación, o laboren en cualquier actividad de comunicación».

El valor que confirió el poder constituyente ecuatoriano a esta materia se reflejó en el apartado cuarto de la disposición transitoria primera de la Constitución donde estableció que el legislativo debía aprobar una ley de comunicación en el plazo de 360 días tras su entrada en vigor. Con retraso, el citado mandato constitucional se cumplió mediante la aprobación de la LOC, de 14 de junio de $2013^{9}$.

Para tener una visión integral del contenido de las libertades de comunicación en Ecuador resulta necesario acudir a las declaraciones internacionales de derechos ${ }^{10}$, en especial al art. 13 de la Convención Americana sobre Derechos Humanos, que reconoce la libertad de pensamiento y de expresión de la siguiente manera: «toda persona tiene derecho a la libertad de pensamiento y de expresión. Este derecho comprende la libertad de buscar, recibir y difundir informa-

9 La ley ha sido objeto de desarrollo mediante el reglamento general a la Ley Orgánica de Comunicación publicado el 27 de enero de 2014.

${ }^{10}$ Se trata de una referencia obligada, pues el art. 11 de la Constitución ecuatoriana afirma que «los derechos y garantías establecidos en la Constitución y en los instrumentos internacionales de derechos humanos serán de directa e inmediata aplicación». Además de la citada cláusula general, el art. 384.2 del aludido texto sostiene que «el Estado formulará la política pública de comunicación, con respeto irrestricto de la libertad de expresión y de los derechos de la comunicación consagrados en la Constitución y los instrumentos internacionales de derechos humanos». 
ciones e ideas de toda índole, sin consideración de fronteras, ya sea oralmente, por escrito o en forma impresa o artística, o por cualquier otro procedimiento de su elección ${ }^{11} \gg$. Para interpretar el alcance del citado precepto resulta necesario acudir a la jurisprudencia de la Corte Interamericana de Derechos Humanos (en adelante, Corte Interamericana) y a la Declaración de principios sobre libertad de expresión elaborada por la Comisión Interamericana de Derechos Humanos ${ }^{12}$.

\section{LA VISIÓN DEMOCRÁTICA DE LAS LIBERTADES DE EXPRESIÓN E INFORMACIÓN COMO PREMISA DE LA LEY ORGÁNICA DE COMUNICACIÓN}

La LOC se aprobó con la finalidad de asegurar el pleno y eficaz ejercicio de las libertades de expresión e información y fortalecer la participación ciudadana. En otras palabras, supone una revisión o superación de la teoría liberal de la libertad de expresión y, por ello, contempla la posibilidad de que los poderes públicos fomenten su ejercicio efectivo.

El inicial liberalismo justificó la necesidad de proteger la libertad de expresión frente a los poderes públicos porque constituía un método para alcanzar la verdad, se erigía como un cauce pacífico para dirimir las divergencias inherentes a toda sociedad plural y era un instrumento para ilustrar a la población en general $^{13}$. A medida que se va democratizando el Estado, se advirtió la importancia de la libertad de expresión para su funcionamiento. La prensa, al hacer públicos los asuntos generales, permite el control político y fomenta el asociacionismo de los ciudadanos en torno a las ideas ${ }^{14}$. La libertad de prensa es esencial para el sistema representativo puesto que permite a los electores conocer las ideas y

${ }^{11}$ El art. 14 de la CADH también reconoce el derecho de rectificación o respuesta del siguiente modo: «Toda persona afectada por informaciones inexactas o agraviantes emitidas en su perjuicio a través de medios de difusión legalmente reglamentados y que se dirijan al público en general, tiene derecho a efectuar por el mismo órgano de difusión su rectificación o respuesta en las condiciones que establezca la ley».

${ }^{12} \mathrm{Si}$ bien este último documento no es vinculante para los Estados, se considera que tiene un importante valor interpretativo.

Asimismo, resultan relevantes las opiniones consultivas OC-5/85, de 13 de noviembre de 1985, sobre la colegiación obligatoria de periodistas y OC-7/86, de 29 de agosto de 1986, sobre la exigibilidad del derecho de rectificación o respuesta.

13 Sobre la fundamentación de la libertad de imprenta en las Cortes de Cádiz, entre otros, véase Magdaleno Alegría, A. (2013). «La libertad de imprenta como premisa de la primera Constitución racional-normativa española: la Constitución de Cádiz de 1812», Revista de Derecho Político, núm. 87 , págs. 228 y ss.

${ }^{14}$ De Tocqueville, A. (1989) La democracia en América, Madrid, Aguilar, pág. 382. 
conductas de los candidatos y, de esta manera, permite elegirlos con fundamento. En consecuencia, la protección de las libertades de comunicación no sólo se justifica en el exclusivo interés del sujeto individual, en la preservación del libre desarrollo de su personalidad, sino también en el hecho de que la libre difusión de opiniones e informaciones posibilita la libre formación de la opinión pública y, en definitiva, el funcionamiento del sistema democrático. Así, por ejemplo, cuando se protege el secreto o reserva del periodista de sus fuentes de información, el ordenamiento jurídico no sólo preserva el interés subjetivo del periodista en obtener la información para su posterior difusión, sino también el derecho de la comunidad política entera a recibir esta información de interés público. La importancia de las libertades de expresión e información en el Estado democrático ha hecho que diversos tribunales de distintos Estados hayan sostenido su preponderancia en el caso de que plantee un conflicto con otros derechos fundamentales o bienes constitucionales. En este sentido, la Corte Interamericana ha afirmado en varias ocasiones que la libertad de expresión es una «piedra angular en la existencia misma de una sociedad democrática» y que «sin una efectiva garantía de la libertad de expresión se debilita el sistema democrático y sufren quebranto el pluralismo y la tolerancia; los mecanismos de control y denuncia ciudadana pueden volverse inoperantes y, en definitiva, se crea un campo fértil para que arraiguen sistemas autoritarios» ${ }^{15}$. Como correlato de este postulado, la Corte Interamericana mantiene que «las sanciones penales y su severidad nunca deberían ser utilizadas como un recurso para sofocar el debate público sobre cuestiones de interés general y para limitar la crítica a los funcionarios en el ejercicio de sus funciones, al Estado o sus instituciones». Asimismo, la Corte Interamericana afirma que «las expresiones concernientes al ejercicio de funciones de las instituciones del Estado gozan de una mayor protección, de manera tal que se propicie el debate democrático en la sociedad ${ }^{16}{ }_{»}$.

Desde la perspectiva de la teoría liberal de los derechos fundamentales, los derechos suponen la protección de una esfera de actuación de los ciudadanos, un haz de facultades sobre las que, en principio, el Estado no puede intervenir. El Estado es el enemigo de la libertad de expresión y, por ello, se establecen medidas como la prohibición de la censura previa o del secuestro administrativo. Corresponde en exclusiva a los individuos procurarse los medios materiales para

15 Caso Vélez Restrepo y familiares vs. Colombia, de 3 de septiembre de 2012, párr. 141.

${ }^{16}$ Caso Usón Ramírez vs. Venezuela, de 20 de noviembre de 2009, párrs. 69 y 83 ss.

En el ámbito del Convenio Europeo de los Derechos Humanos, véase STEDH de 7 de diciembre de 1976, «caso Handyside» y STEDH de 8 de julio de 1986, «caso Ligens». 
el ejercicio de los derechos. El pluralismo de los medios de comunicación debe ser fruto natural del ejercicio subjetivo de las libertades individuales ${ }^{17}$.

Ahora bien, para que las ideas e informaciones puedan ser capaces de contribuir eficazmente a la formación de la opinión pública resulta necesario emitirlas a través de medios aptos para llegar a una gran audiencia compuesta por los millones de ciudadanos que conviven en los Estados, esto es, se precisa de medios de comunicación de masas (prensa escrita, radio, televisión, etc. ${ }^{18}$. Los medios de comunicación resultan sumamente costosos y, por tanto, sólo aquellos sujetos, grupos sociales o económicos que disponen de los recursos suficientes son capaces de difundir ideas, opiniones e informaciones ante la opinión pública ${ }^{19}$. Un reducido número de propietarios tienen la capacidad real de determinar qué es noticia y cómo es noticia, así como las ideas y opiniones que son difundidas a la opinión pública, en definitiva, dominan la agenda política y social. Que sólo un reducido grupo de la sociedad tenga acceso real al libre mercado de las ideas provoca el funcionamiento deficitario del sistema democrático, no se produce un debate desinhibido y vigoroso, pues no todos tienen las mismas oportunidades reales de expresar sus opiniones e informaciones. La opinión pública queda mediatizada y empobrecida puesto que, al carecer de recursos suficientes, muchos ciudadanos y grupos sociales no tienen oportunidades reales de poder competir en el libre mercado de las ideas. El empobrecimiento del debate público acarrea un mal funcionamiento del sistema político y de la calidad de las decisiones colectivas ${ }^{20}$.

Frente a la abstención propugnada por el Estado liberal y al objeto de asegurar el pluralismo, entendido como valor fundamental del Estado, las Constituciones y los ordenamientos jurídicos de diferentes Estados democráticos contemplan diversas medidas de intervención al objeto de garantizar el pluralismo.

17 Véase Bastida Freijedo, F. (2002). «Pluralismo y medios de comunicación», en Tornos Mas, J. (Coord.): Democracia y medios de comunicación, Valencia, Tirant lo Blanch, pág. 66.

${ }^{18}$ Se podría objetar a lo dicho supra que las nuevas tecnologías de la información y de la comunicación, especialmente las redes sociales, también son aptos para cumplir esta función. Si bien no se niega su importancia, se considera que, por el momento, la radio y la televisión son los medios más influyentes y con mayor difusión, mientras que en el caso de las TICS su uso todavía no es generalizado y, además, hay grandes dificultades para alcanzar visibilidad en la red.

19 El proceso de la mundialización económica, la concentración de capitales y el desarrollo de nuevas tecnologías para la difusión de contenidos ha generado la aparición de grandes grupos mediáticos que son propiedad de grandes conglomerados empresariales y financiaros que han transformado la manera de ejercer el periodismo. A modo de ejemplo, véase RAMONET, I. (2011). La explosión del periodismo. De los medios de masas a la masa de medios, Madrid, Clave intelectual, en concreto, págs. 41 y ss.

${ }^{20}$ Sobre la cuestión, véase Fiss, O. (1999). La ironía de la libertad de expresión, Barcelona, Gidesa, en especial págs. 74 y ss. 
Ejemplos de las citadas medidas son: normas para evitar la concentración en los medios de comunicación, evitando así posiciones de prevalencia en el proceso de libre formación de la opinión pública; el derecho de rectificación o de réplica; el derecho de acceso a los medios de comunicación públicos de los grupos sociales y políticos más significativos; regulaciones especiales para los medios de comunicación públicos y privados durante la campaña electoral a fin de asegurar la igualdad de oportunidades entre los competidores; la creación de administraciones independientes audiovisuales para asegurar el pluralismo y la libre formación de la opinión pública. A tal efecto, entre otras atribuciones, designan los presidentes de los medios de comunicación públicos, determinan los concesionarios de frecuencias de emisión de radio y televisión, adoptan medidas contra las concentraciones de los medios de comunicación, etc. ${ }^{21}$. Asimismo algunos ordenamientos consideran que los medios de comunicación tienen una importante responsabilidad social y, por tanto, se deben priorizar las funciones educativas y culturales de los mismos ${ }^{22}$.

En coherencia con las ideas expuestas ${ }^{23}$, el art. 384 de la Constitución de Ecuador prevé que la comunicación social debe asegurar el ejercicio de los dere-

${ }^{21}$ Sobre la materia, entre otros, véanse Arenas Ramiro, M. (2015) «El régimen jurídico de los medios de comunicación en Alemania», Teoría y Realidad Constitucional, núm. 36, págs. 539-588; Barata I Mir, J. (2006), Democracia y audiovisual, Marcial Pons, Madrid; Belando Garín, B. y Montiel Roig, G. (Coords.) (2011), Contenidos y mercado en la regulación de la Comunicación audiovisual, Tirant lo Blanch, Valencia; Pavani, G. (2015). «El régimen de los medios de comunicación en Italia. El sistema de radio y televisión: ¿Una anomalía en el contexto comparado?», Teoría y Realidad Constitucional, núm. 36, págs. 459-496; Poptcheva, E.M. «Las autoridades independientes de control de los medios de comunicación audiovisual en Alemania», en GAVARA DE CARA, J. C. y De Miguel BÁrCena J. (Eds.) (2013). La autorregulación de los medios de comunicación como sistema de control, Barcelona, Bosch, pág. 289-309; RoIG, A. «La autoridad independiente de control de los medios de comunicación audiovisual en Francia», en Gavara de Cara J. C. (Ed.) (2013) Las autoridades independientes de control de los medios de comunicación audiovisual, Barcelona, Boch, págs. 267-285.

${ }^{22}$ Gavara de Cara, J. C.: «La autorregulación como mecanismo de autocontrol de los medios de comunicación: intervención pública y regulación interna», en GAVARA DE CARA, J. C. y De Miguel BÁrcena J. (eds.) (2013). La autorregulación de los medios de comunicación como sistema de control, Barcelona, Bosch, pág. 26.

23 Téngase en cuenta que existen dos concepciones democráticas distintas sobre el pluralismo, que son la democrático-funcional y la democrático procedimental. Según la primera, el ámbito de reconocimiento de las libertades de comunicación está condicionando por el fin a perseguir, esto es, el pluralismo. Como afirma el profesor BASTida, la opinión pública libre sólo es aquella que se forma en los valores liberal-democráticos, no en valores contrarios o contraculturales, que han de quedar silenciados o marginados. Desde la segunda perspectiva, las libertades de comunicación no deben ser entendidas como un instrumento destinado a satisfacer su función social, es decir, la formación de la opinión pública libre, sino que ante todo son derechos subjetivos cuyo libre ejer- 
chos a la comunicación, la información y la libertad de expresión, así como fortalecer la participación ciudadana. El artículo 17 del mismo texto fundamental mantiene que el Estado fomentará la pluralidad y la diversidad en la comunicación, y a tal efecto distribuirá mediante métodos transparentes y en condiciones de igualdad las frecuencias del espacio radio-eléctrico; facilitará la creación de medios de comunicación públicos, privados y comunitarios; y no permitirá monopolios u oligopolios en los medios de comunicación y en el uso de las frecuencias. En desarrollo del citado precepto, la LOC establece medidas que tratan de evitar las posiciones de prevalencia de los sectores sociales que poseen mayores recursos, como la prohibición de que el sector financiero posea la propiedad de los medios de comunicación o desarrolla medidas para evitar concentraciones en la propiedad de los medios de comunicación; fomenta la creación de medios de comunicación comunitarios ${ }^{24} \mathrm{y}$, asimismo, les reserva un tercio en la concesión de radiofrecuencias con la finalidad de garantizar el acceso en condiciones de igualdad al espacio radioeléctrico, etc. ${ }^{25}$.

\section{ESTUDIO DE LOS ASPECTOS MÁS CONTROVERTIDOS DE LA LOC}

\subsection{La discutible calificación como servicio público de la actividad de los medios de comunicación}

El art. 71 LOC establece que «la comunicación social que se realiza a través de los medios de comunicación es un servicio público», independientemente del

cicio permite crear el libre mercado de las ideas. En este sentido, lo importante es «la formación libre de la opinión pública, no la formación de una opinión pública libre». Véase Bastida Freijedo, F. (2012). «Pluralismo y medios de comunicación», ob. cit., págs. 76 y ss. Sobre la cuestión, asimismo Villaverde Menéndez, I. (1995). Los derechos del público, Madrid, Tecnos, pág. 29 y ss.

${ }^{24}$ Según el art. 85 LOC, «los medios de comunicación comunitarios son aquellos cuya propiedad, administración y dirección corresponden a grupos u organizaciones sociales sin fines de lucro, a comunas, comunidades, pueblos y nacionalidades». El art. 86 del citado texto normativo prevé medidas de acción positiva como, por ejemplo, la concesión de créditos preferentes, la exención de impuestos o el acceso a cursos de capacitación profesional.

${ }^{25} \mathrm{La}$ Corte Interamericana entiende que los Estados deben jugar un papel activo en el fomento del pluralismo informativo. Concretamente, afirma que: «el Estado no sólo debe minimizar las restricciones a la circulación de la información sino también equilibrar, en la mayor medida de lo posible, la participación de las distintas informaciones en el debate público, impulsando el pluralismo informativo. En consecuencia, la equidad debe regir el flujo informativo. En estos términos puede explicarse la protección de los derechos humanos de quien enfrenta el poder de los medios y el intento por asegurar condiciones estructurales que permitan la expresión equitativa de las ideas». Caso Fontevecchia y D’Amico vs. Argentina, de 29 de noviembre de 2011, párr. 45. 
medio a través el que se ejerce (prensa escrita, radio, televisión, etc.) o de su titularidad pública o privada ${ }^{26}$. La Corte Constitucional ha avalado la constitucionalidad de esta normativa e, incluso, infiere del texto constitucional que el ejercicio de los derechos de comunicación debe garantizarse «necesariamente mediante la prestación de un servicio público ${ }^{27} »$. De hecho, la Corte justifica la intervención del Estado en la necesidad de coadyuvar a la consecución de su pleno ejercicio enfocado hacia todos los miembros de la sociedad ${ }^{28}$.

Son variados los motivos por los que se considera injustificada esta medida, entre los que pueden destacarse los que se señalarán a continuación:

En primer lugar, se trata de una categoría que casa bastante mal con la actividad de la generalidad de los medios de comunicación ${ }^{29}$. La Constitución ecuatoriana hace referencia a los servicios públicos como una actividad prestacional de las distintas Administraciones públicas ${ }^{30}$, si bien admite la posibilidad de regular

${ }^{26}$ El art. 5 LOC considera como medios de comunicación social a «las empresas, organizaciones públicas, privadas y comunitarias, así como a las personas concesionarias de frecuencias de radio y televisión, que prestan el servicio público de la comunicación masiva que usan como herramientas medios impresos o servicios de radio, televisión y audio y video por suscripción, cuyos contenidos pueden ser generados o replicados por el medio de comunicación a través de internet».

${ }^{27}$ Véase Sentencia de la Corte Constitucional de Ecuador núm. 003-14-SIN-CC, de 14 de septiembre de 2014, pág. 58

28 Sentencia de la Corte Constitucional de Ecuador núm. 003-14-SIN-CC, de 14 de septiembre de 2014, pág. 62. Sobre una postura similar en la doctrina española en referencia a la televisión, véase CHinchilla Marín, C. «El servicio público, ¿una amenaza o una garantía para los derechos fundamentales? Reflexiones sobre el caso de la televisión», en MARTín RETORTILlo, S. (Coord.) (1991) Estudios sobre la Constitución española: Homenaje al profesor Eduardo García de Enterría, Vol. II, Madrid, Civitas, págs. 964 y ss.

29 En el ámbito europeo muchos Estados calificaron la radio y la televisión como un servicio público en régimen de monopolio sin perjuicio del otorgamiento de las oportunas concesiones administrativas, fundamentado esta opción en la declaración de dominio público del espacio radioeléctrico o en la necesidad de regular su uso debido a su carácter limitado. En cuanto a la prensa escrita, los Estados europeos han realizado una interpretación liberal, en el sentido de entender que su mejor garantía es la no intervención de los poderes públicos.

Con el paso del tiempo, el argumento del peligro de un oligopolio natural privado como consecuencia de la escasez del espacio radioeléctrico y de su coste inasumible para la gran mayoría de los ciudadanos dejó de tener sentido como consecuencia de los nuevos avances tecnológicos en la transmisión de la información. A partir de ese momento, se pasa a una concepción funcional del concepto de servicio público porque es la mejor manera de garantizar el pluralismo. Véase BASTIDA Freijedo, F. (2002). «Pluralismo y medios de comunicación», ob. cit., pág. 74.

30 A modo de ejemplo, el art. 264.4 de la Constitución ecuatoriana establece que los gobiernos locales tienen competencias, entre otras materias, en «prestar los servicios públicos de agua potable, alcantarillado, depuración de aguas residuales, manejo de desechos sólidos, actividades de saneamiento ambiental y aquellos que establezca la ley». Por su parte, la Corte Constitucional de Ecuador define como servicio público «toda actividad que se efectúa en beneficio de un con- 
mediante ley servicios públicos al objeto de posibilitar el efectivo ejercicio de los derechos fundamentales. Ahora bien, la extensión de la categoría de servicio público a todos los medios de comunicación con la misma intensidad resulta, cuanto menos, sospechosa de ser un intento de interferir en el desarrollo de la actividad de los medios de comunicación privados. Intervención fuerte o intensa que se hace patente en el hecho de no sólo se circunscribe a la comunicación audiovisual, sino que también incluye a la prensa escrita ${ }^{31}$. De acuerdo al principio de proporcionalidad, la medida que afecte a los derechos fundamentales, además de idónea, debe ser necesaria, esto es, no deben existir medidas menos gravosas para alcanzar, con igualdad de eficacia, la finalidad perseguida ${ }^{32}$. La

junto de destinatarios quienes, por la existencia de un interés general o común, demandan la prestación de los mismos a los cuales les compete un régimen especial, dada la relevancia social que comporta. En este sentido, los servicios públicos constituyen prestaciones que satisfacen una necesidad de interés general, cuya cobertura puede realizarse a través de la gestión directa del Estado o, a través de entes privados, tal y como establece el marco constitucional vigente». Véase Sentencia de la Corte Constitucional de Ecuador núm. 003-14-SIN-CC, de 14 de septiembre de 2014, pág. 57.

${ }^{31}$ Por el contrario al modelo analizado supra, la mayoría de los Estados europeos suelen regular de manera separada el régimen de la prensa y la radio y televisión. En el caso de la prensa escrita rige el principio de libertad, si bien varios Estados han establecido reglamentaciones al objeto de evitar su concentración y, de esta forma, asegurar su pluralismo externo. En el caso francés, la decisión del Consejo Constitucional francés de 10 y 11 de octubre de 1984 entendió que respecto a la libertad de prensa no cabe un entendimiento exclusivamente liberal, esto es, que el Estado debe limitarse a dejar hacer, sino que, por el contrario, al objeto de asegurar el derecho de los lectores a ser informados, resulta admisible la posibilidad de establecer limitaciones del derecho a la propiedad o a la libertad de empresa para limitar la concentración de medios. En otras palabras, caben acciones positivas para asegurar el pluralismo de la prensa nacional, departamental o local, pues el pluralismo de los diarios de información política y general es un objetivo constitucional. Resulta necesario asegurar al público un número suficiente de publicaciones con diversidad de tendencias. Sobre el pluralismo informativo como objetivo de valor constitucional en el ordenamiento constitucional francés, véase Rallo LombarTe, A. (2000). «La garantía del pluralismo informativo en Francia. El Conseil Supérieur de L'audiovisuel», Revista española de Derecho Constitucional, núm. 50, págs. 98 y ss.

${ }^{32}$ La Corte Interamericana aplica el principio de proporcionalidad a la hora de valorar si una determinada restricción de la libertad de expresión es compatible con el régimen de protección dispensado por el art. 13 del CADH. Así, en primer lugar, examina la necesidad de la restricción en un sociedad democrática, entendiendo por «necesaria» la existencia de una necesidad social imperiosa que justifique la restricción. En segundo lugar, analiza la adecuación de la medida para la consecución del fin que se persigue y, por ello, «la Corte debe examinar las alternativas existentes para alcanzar el fin legítimo perseguido y precisar la mayor o menor lesividad de aquéllas». Y, finalmente, analiza la proporcionalidad en sentido estricto de la restricción, lo que implica examinar «si la restricción resulta estrictamente proporcional, de tal forma que el sacrificio inherente a aquélla no resulte exagerado o desmedido frente a las ventajas que se obtienen mediante tal limi- 
finalidad de la norma, que consiste en asegurar el ejercicio efectivo de los derechos fundamentales, se puede alcanzar mediante otras opciones menos restrictivas para los derechos fundamentales de los particulares como, por ejemplo, regulando e implantando medios de comunicación públicos e independientes que actúen en libre concurrencia con el resto de medios y que tengan la misión de fortalecer y reflejar el pluralismo o, en relación a los medios de comunicación privados, estableciendo unos deberes de distinta intensidad en referencia a su contribución a la libre formación de la opinión pública. La regulación dada por el legislador ecuatoriano no ha establecido medidas menos restrictivas para alcanzar el fin constitucional buscado, por lo que merece el reproche constitucional.

En segundo lugar, la utilización de la categoría de servicio público para calificar la actividad de todos los medios de comunicación, independientemente de su titularidad, modalidad o tamaño, imponiendo por igual unos mismos deberes, también resulta claramente desproporcionada.

La prensa escrita no debería regularse de la misma manera que los medios audiovisuales. Eso sí, resulta necesario asegurar su pluralismo externo, en consecuencia, se aboga por regular medidas de anticoncentración al objeto de evitar posiciones dominantes en el proceso de formación de la opinión pública, postura que resulta coherente con el mandato de fomentar la pluralidad y diversidad en la comunicación establecido en el art. 17 de la Constitución de Ecuador ${ }^{33}$.

La radio y la televisión, dada su mayor capacidad de influencia en la formación de la opinión pública y la necesidad de regular el aprovechamiento del espacio radioeléctrico y garantizar el pluralismo, han justificado distintos tipos de regulaciones con diferentes grados de intervención en derecho comparado ${ }^{34}$. Sin

tación». Véanse, respectivamente, caso Fontevecchia y D’Amico vs. Argentina, de 29 de noviembre de 2011, párr. 54, y Caso Usón Ramirez vs. Venezuela, de 20 de noviembre de 2009, párrs. 72 y 79 .

3 La prohibición de incluir información institucional en la prensa escrita también podría coadyuvar a preservar su independencia del poder ejecutivo.

34 Varios Estados europeos poseen normas de Derecho Público para regular la radio y la televisión con el objeto de garantizar su pluralismo como consecuencia de su gran influencia en el proceso de la formación de la opinión pública. En el caso francés, la decisión núm. 88-248, de 17 de enero de 1989, del Consejo Constitucional entendió que corresponde al legislador conciliar el ejercicio de la libertad de comunicación con, de un lado, las limitaciones técnicas inherentes a los medios de comunicación audiovisual y, de otro lado, la preservación del carácter pluralista de las corrientes de expresión socioculturales contra los cuales estos modos de comunicación, por su influencia considerable, son susceptibles de atentar. Para alcanzar los citados objetivos el Consejo constitucional admite la posibilidad de someter las diferentes categorías de servicios de comunicación audiovisual a un régimen de autorización administrativa otorgada por una autoridad administrativa independiente. 
embargo, la LOC no diferencia en cuando a los deberes derivados de la calificación de servicio público entre los medios de radio y televisión públicos y privados. En el modelo europeo la tendencia general consiste en calificar como servicio público la actividad de los medios de comunicación públicos, requiriéndoles una serie de deberes en cuando a su organización y funcionamiento muy intensos. Mientras que en el caso de las radios y televisiones privadas se establecen unos deberes de menor intensidad que tienen por objeto garantizar el pluralismo informativo y su observancia se controla por una autoridad independiente ${ }^{35}$.

El modelo alemán se ha construido esencialmente a través de diversos pronunciamientos del Tribunal Constitucional (aproximadamente catorce) conocidas como las sentencias de la radiotelevisión. Entre otras cuestiones, el citado tribunal ha interpretado que la libertad de información a través de los medios de comunicación tiene una entidad diferenciada de la propia de la libertad de información. Se trata de una libertad al servicio de una función, que se corresponde con garantizar y proteger la formación de la opinión pública libre. Como afirma Arenas Ramiro, «el concepto de servicio público se caracteriza, además de por obedecer a un mandato constitucional, por tres elementos: un medio técnico de transmisión que asegura a todos los ciudadanos la recepción de los programas televisivos; una programación que se corresponde por su objetivo y por el tipo de programa, con el mandato de informar, formar y entretener; y por el valor del pluralismo y equilibrio en la programación, que se garantiza, sobre todo, a través de normas de organización y procedimiento». Como se desprende de la jurisprudencia del TC alemán, la prestación del servicio esencial de televisión en Alemania es dual. En primer lugar, compete a la televisión pública y, como complemento, también a la televisión privada, como concesionaria de un servicio público, si bien es cierto que posee mayor autonomía a la hora de establecer su programación y enfoque. Véase Arenas Ramiro, M. (2015) «El régimen jurídico de los medios de comunicación en Alemania», ob. cit., pág. 541.

35 A modo de ejemplo, en el modelo dual alemán de televisión pública y privada, los medios audiovisuales privados deben cumplir con la función de servicio público que se corresponde con la obligación de establecer una programación los más plural y equilibrada posible, eso sí, dispone de mayor autonomía para seleccionar sus contenidos y formatos. Corresponde a las Instituciones de los Medios, órganos independientes creados por las leyes de comunicación, garantizar su pluralismo. Los componentes de los citados órganos son nombrados por los Parlamentos de los Lander y por los representantes de los grupos sociales más importantes. Entre sus funciones se encuentra la garantía de la libertad de televisión y, por tanto, la libre formación de la opinión pública en aludido ámbito. En concreto, gestionan y autorizan las licencias a los medios privados, controlan su programación, etc. Sobre la cuestión, entre otros, véanse Arenas Ramiro, M. (2015) «El régimen jurídico de los medios de comunicación en Alemania», ob. cit., págs. 566 y ss; PoPTCHEVA, E.M. «Las autoridades independientes de control de los medios de comunicación audiovisual en Alemania», ob. cit., págs. 299 y ss; CAPPUCCIO, L. (2013). «Las autoridades independientes de control de los medios de comunicación audiovisual en Italia», en Gavara De CARA, J. C. y De Miguel Bárcena J. (eds.) La autorregulación de los medios de comunicación como sistema de control, ob. cit., págs. 251 y ss; PAVANI, G. (2015). «El régimen de los medios de comunicación en Italia. El sistema de radio y televisión: ¿Una anomalía en el contexto comparado?», ob. cit., págs. 488 y ss. Asimismo resulta pertinente la lectura de la Recomendación del Consejo de Europa sobre el pluralismo de los medios, adoptada por el Consejo de Ministros el 20 de diciembre de 2000. 
La desproporción también resulta como consecuencia de que la LOC establece unos mismos deberes tanto para los medios generalistas como para los que tienen una especialización temática (cultura, religión, deporte, etc.). La norma trata de manera igual lo que, en realidad, es desigual.

En tercer lugar, la calificación como servicio público de la actividad de los mass media podría suponer que la libertad de información resulte irreconocible, en la medida que afecta al haz de facultades que protege. La norma se adscribe a una visión democrático-funcional de las libertades de expresión e información, si bien se excede en cuando a la imposición de determinados deberes si se compara con otros modelos de derecho comparado. Limita, en ocasiones, excesivamente la libertad del concreto medio de comunicación al exigirle determinados deberes como, por ejemplo, informar sobre todos los asuntos de interés general. El recurso al servicio público parece conllevar un entendimiento de las libertades de expresión e información exclusivamente al servicio del sistema democrático ${ }^{36}$, convierte la libertad de información en un servicio público a beneficio de la comunidad $^{37}$. De hecho, se considera que la Corte Constitucional fundamenta la constitucionalidad de la LOC mediante una comprensión criticable de la doble dimensión de las libertades de expresión e información ${ }^{38}$, pues parece inferir del derecho a recibir información veraz un derecho de prestación que, además, no sólo lo deben satisfacer los poderes públicos, sino también los particulares ${ }^{39}$. Una

36 Desde un punto de vista similar, Villaverde MenéndeZ afirma que: «la libertad de expresión no puede ser (...) un mecanismo jurídico para proteger únicamente las ideas, opiniones o informaciones verdaderas, correctas o democráticamente valiosas, porque se transformaría en un instrumento coactivo. Ni siquiera debiera ser un instrumento normativo para proteger más un modo de actuar individual dirigido a alcanzar esos resultados. De servir a ese fin la libertad de expresión ya no protegería la autodeterminación individual sobre la propia conducta sustraída a cualquier género de imposiciones unilaterales y heterónomas de deberes coactivos (poder público), sino todo lo contrario, el ejercicio de una función pública». Véase Villaverde Menéndez, I. (2003). «La revisión de los modelos clásicos de proceso de comunicación pública, Revista Española de Derecho Constitucional, núm. 68, pág. 129.

${ }^{37}$ La citada concepción es sintetizada por VILLAVERDE de la siguiente manera: «la información se concibe como un bien útil a la colectividad y sus fuentes como servicio objetivamente público. Quienes participan en el uso y disfrute de ese servicio, lo deben hacer en las condiciones que establecen las normas que lo regulan, porque ellas garantizan el uso correcto del bien información». Villaverde MenéndeZ, I. (1995). Los derechos del público, ob. cit., pág. 30.

38 De hecho, la Corte Constitucional llega a afirmar que la satisfacción de los derechos a la comunicación y a la información, que configuran parte del contenido constitucional de los derechos del buen vivir, deben garantizarse «necesariamente mediante la prestación de un servicio público». Sentencia de la Corte Constitucional de Ecuador núm. 003-14-SIN-CC, de 14 de septiembre de 2014, pág. 58.

39 Ibidem, pág. 75. 
cosa es el reconocimiento de que las libertades de expresión e información tienen una doble dimensión ${ }^{40}$ y admitir la posibilidad de suplir las carencias del mercado mediante la acción de los medios de comunicación públicos o estableciendo una calidad de las informaciones ${ }^{41}$; y otra cosa bien distinta es obligar a cada uno de los medios de comunicación a contribuir a la formación de una opinión pública óptima desde la perspectiva de las necesidades del Estado democrático, y en caso contrario ser sancionados ${ }^{42}$. El papel de los poderes públicos en materia de comunicación pública debe ser de fomento de su ejercicio efectivo y de garantía del pluralismo como resultado global, pero no establecer una concepción de servicio público que asegure una especie de derecho de prestación que debe ser facilitado por cada medio de comunicación.

${ }^{40}$ La Corte Interamericana participa de esta compresión. Así, afirma: «la libertad de expresión tiene una dimensión individual y una dimensión social, de las cuales ha desprendido una serie de derechos que se encuentran protegidos en dicho artículo. Este Tribunal ha afirmado que ambas dimensiones poseen igual importancia y deben ser garantizadas plenamente en forma simultánea para dar efectividad total al derecho a la libertad de expresión en los términos previstos por el artículo 13 de la Convención». «La primera dimensión de la libertad de expresión comprende el derecho a utilizar cualquier medio apropiado para difundir opiniones, ideas e información y hacerlo llegar al mayor número de destinatarios. En este sentido, la expresión y la difusión son indivisibles, de modo que una restricción de las posibilidades de divulgación representa directamente, y en la misma medida, un límite al derecho de expresarse libremente. Con respecto a la segunda dimensión del derecho a la libertad de expresión esto es, la social, la Corte ha señalado que la libertad de expresión implica también el derecho de todos a conocer opiniones, relatos y noticias vertidas por terceros. Para el ciudadano común tiene tanta importancia el conocimiento de la opinión ajena o de la información de que disponen otros como el derecho a difundir la propia. Es por ello que a la luz de ambas dimensiones, la libertad de expresión requiere, por un lado, que nadie sea arbitrariamente menoscabado o impedido de manifestar su propio pensamiento y representa, por tanto, un derecho de cada individuo; pero implica también, por otro lado, un derecho colectivo a recibir cualquier información y a conocer la expresión del pensamiento ajeno». A modo de ejemplo, véase caso Vélez Restrepo y familia vs. Colombia, de 3 de septiembre de 2012, párr. 137 y ss.

${ }^{41}$ Así, por ejemplo, la regulación del derecho de rectificación o réplica obliga a los medios de comunicación a que publiquen o difundan una versión alternativa dada por el sujeto aludido por las informaciones, cuestión que produce un efecto beneficioso en la formación de la opinión pública, en tanto que los ciudadanos tienen la posibilidad de conocer dos versiones alternativas sobre un mismo hecho. No se pide al medio de comunicación que informe o no informe, sino que si lo hace, en determinadas circunstancias, debe permitir al sujeto aludido por la información publicar o difundir una versión alternativa.

42 En palabras de la propia Corte, «la interpretación convencional y constitucional de la categorización a la comunicación como servicio público se traduce en la obligación estatal de generar el ambiente propicio para el intercambio de ideas, sin interferencias directas o indirectas, lo cual asegura una sociedad democrática». Sentencia de la Corte Constitucional de Ecuador núm. 003-14-SIN-CC, de 14 de septiembre de 2014, pág. 68. 


\subsection{La inapropiada utilización del concepto de censura previa y la obligatoriedad de informar sobre asuntos de interés público}

El art. 18 LOC prohíbe la censura previa, entendiendo como tal dos acciones distintas: de un lado, cuando «una autoridad, funcionario público, accionista, socio, anunciante o cualquier otra persona en el ejercicio de sus funciones o en su calidad revise, apruebe o desapruebe los contenidos previos a su difusión a través de cualquier medio de comunicación a fin de obtener de forma ilegítima un beneficio propio, favorecer a una tercera persona y/o perjudicar a un tercero». De otro lado, cuando los medios de comunicación omitan de manera deliberada y recurrente la difusión de hechos de interés público. Vía reglamentaria, se añade que se tratará de censura previa «cuando dicho ocultamiento se hace con el fin de obtener de forma ilegítima un beneficio propio, favorecer a una tercera persona y/o perjudicar a un tercero ${ }^{43} \gg$. Como se observa, la LOC distingue dos tipos de censura previa, una primera, genérica, que se comete por una autoridad pública o por un socio, accionista o anunciante respecto de los contenidos comunicativos; y una segunda, asimilada, que se produce cuando los medios de comunicación omiten informar sobre cuestiones de interés general ${ }^{44}$.

Se trata de una regulación que genera numerosos reparos, entre los que se destacarán los siguientes.

A) De un lado, en referencia a la censura previa genérica, se pueden formular las siguientes apreciaciones críticas.

En primer lugar, el art. 18 LOC no concuerda con el concepto de censura previa generalmente admitido. Las primeras reivindicaciones a favor del reconocimiento de la libertad de imprenta fueron frente al Estado, reclamaron la ausencia de interferencias previas por parte de los poderes públicos o eclesiásticos en la libre difusión de las ideas a través de los escritos, esto es, fueron alegatos contra la obligatoriedad de someter a examen y aprobación de las autoridades los escritos antes de su difusión pública ${ }^{45}$. Por ello, los distintos textos constitucionales occidentales y, posteriormente, los tratados internacionales, incluyeron entre el elenco de garantías específicas de las libertades de expresión e información la abolición de la censura previa y el establecimiento de la responsabilidad

43 Art. 11 del Reglamento de desarrollo de la LOC.

${ }_{44}$ Para ambos casos, el segundo párrafo del art. 18 LOC establece que la Superintendencia de la Información y la Comunicación sancionará con una multa pecuniaria de 10 salarios básicos unificados, esto es, aproximadamente 3500 dólares USA.

45 Quizá la obra clásica más influyente en la materia fue Aeropagítica escrita por Jhon Milton en 1644. Véase Milton, J. (2001). Aeropagítica, Madrid, Torres Goyanes. 
posterior por los eventuales daños cometidos mediante su ejercicio ${ }^{46}$. En definitiva, la censura previa se identifica con el examen de los poderes públicos. Por el contrario, en el artículo citado de la LOC se incluye dentro del concepto de censura previa también a sujetos privados como los accionistas, socios, anunciantes o cualquier otra persona que revise, apruebe o desapruebe los contenidos previos a su difusión.

En segundo lugar, la norma resulta confusa. Así, desde la perspectiva de la LOC, para hablar de censura previa de una autoridad o funcionario público parece necesaria la concurrencia de dos requisitos: en primer lugar, realizar una acción que consiste en revisar, aprobar o desaprobar los contenidos comunicativos previos a su difusión a través de cualquier medio de comunicación; y, en segundo lugar, debe hacerlo con una finalidad específica, que consiste en «obtener de forma ilegítima un beneficio propio, favorecer a una tercera persona y/o perjudicar a un tercero». En consecuencia, si los responsables públicos desechan determinados contenidos de los medios de comunicación, pero no se consigue demostrar que lo hicieron para «obtener de forma ilegítima un beneficio propio, favorecer a una tercera persona y/o perjudicar a un tercero», no estarían realizando un acto de censura previa.

En tercer lugar, el hecho de que en los medios de comunicación revisen, aprueben o desaprueben los contenidos se suele producir por dos motivos: de un lado, seleccionar aquellos contenidos que responden a su línea editorial, cuestión que forma parte del haz de facultades protegido por las libertades de expresión e información. De otro lado, evitar difundir públicamente determinados contenidos que pueden generar responsabilidad para el medio como, por ejemplo, una noticia que no se encuentre suficientemente contrastada o impedir la difusión de determinados contenidos que contravengan las normas deontológicas elaboradas por el medio o los profesionales de la información ${ }^{47}$.

46 A modo de ejemplo, véase el art. 13.2 CADH. Sobre la cuestión, la Corte Interamericana ha afirmado que: «cuando por medio del poder público se establecen medios o efectúan acciones para impedir la libre circulación de información, ideas, opiniones o noticias se produce una violación radical tanto del derecho de cada persona a expresarse como del derecho de todos a estar bien informados, de modo que se afecta una de las condiciones básicas de una sociedad democrática. En tal hipótesis se encuentran la censura previa, el secuestro o la prohibición de publicaciones y, en general, todos aquellos procedimientos que condicionan la expresión o la difusión de información al control del Estado». Caso Vélez Restrepo y familiares vs. Colombia, de 3 de septiembre de 2012, párr. 139.

${ }^{47}$ Sobre la cuestión, téngase en cuenta que el art. 22 LOC es bastante exigente con la veracidad de las noticias, pues se establece que «todas las personas tienen derecho a que la información de relevancia pública que reciben a través de los medios de comunicación sea verificada, contrastada, precisa y contextualizada. La verificación implica constatar que los hechos difundidos efec- 
En cuarto lugar, las expresiones «obtener de forma ilegítima un beneficio propio, favorecer a una tercera persona y/o perjudicar a un tercero» parecen excesivamente abiertas y, por ende, con una potencial capacidad para subsumir multitud de conductas, lo que permite una excesiva subjetividad en su aplicación.

B) De otro lado, la censura previa por omisión también merece críticas importantes.

En primer lugar, la obligación de los medios de comunicación de «cubrir y difundir los hechos de interés público» violenta claramente su derecho a establecer y mantener su propia línea editorial. Los medios de comunicación privados tienen derecho a establecer su propia orientación, y partiendo de la misma, seleccionar los asuntos sobre los que se quiere informar a la opinión pública. Así, por ejemplo, el derecho protege la creación de un medio de comunicación adscrito a una tendencia religiosa concreta. El citado medio tendrá interés en informar u opinar sobre actos o declaraciones de sus ministros de culto o sobre decisiones políticas en materia religiosa como, por ejemplo, la regulación de la asistencia religiosa en los centros penitenciarios. Pero, por el contrario, posiblemente no estará interesado en informar sobre una decisión presidencial en materia medioambiental, por muy transcendental que sea para la política nacional del país. En definitiva, se obliga a los medios de comunicación a informar sobre lo que no quieren informar. Además, al no discernir entre medios de comunicación a la hora de establecer la obligación, de alguna forma la norma obliga a los medios de comunicación a ser generalistas y, por tanto, impide especializarse en temas determinados (culturales, sindicales, etc.). En definitiva, el citado precep-

tivamente hayan sucedido. La contrastación implica recoger y publicar, de forma equilibrada, las versiones de las personas involucradas en los hechos narrados, salvo que cualquiera de ellas se haya negado a proporcionar su versión, de lo cual se dejará constancia expresa en la nota periodística. La precisión implica recoger y publicar con exactitud los datos cuantitativos y cualitativos que se integran a la narración periodística de los hechos. Son datos cualitativos los nombres, parentesco, función, cargo, actividad o cualquier otro que establezca conexidad de las personas con los hechos narrados. Si no fuese posible verificar los datos cuantitativos o cualitativos, los primeros serán presentados como estimaciones y los segundos serán presentados como suposiciones. La contextualización implica poner en conocimiento de la audiencia los antecedentes sobre los hechos y las personas que forman parte de la narración periodística. Si las personas que son citadas como fuentes de información u opinión tienen un interés específico o vinculación de orden electoral, política, económica o de parentesco en relación a las personas o a los hechos que forman parte de la narración periodística, esto deberá mencionarse como dato de identificación de la fuente». 
to supone una clara vulneración de la dimensión subjetiva de la libertad de información ${ }^{48}$.

En segundo lugar, el hecho de que la LOC sancione como censura la omisión de «informaciones de interés público» de manera deliberada y recurrente, plantea el doble problema de determinar qué es interés público y, sobre todo, a quién le corresponde fijarlo. La dificultad concretar el concepto de interés público es mayúscula, como lo demuestra el gran número de estudios doctrinales y de pronunciamientos de los tribunales sobre la cuestión ${ }^{49}$.

En tercer lugar, el reglamento de desarrollo de la LOC añade que, para considerar que un medio de comunicación ha incurrido en una censura previa por omisión, el ocultamiento de la información pública se debe realizar «con el fin de obtener de forma ilegítima un beneficio propio, favorecer a una tercera persona y/o perjudicar a un tercero». Resulta cuanto menos criticable que un reglamento complete o altere el contenido de la norma legal, aunque sea para delimitar y, en definitiva, restringir el ámbito de aplicación de la sanción. El añadido posterior reglamentario puede ser interpretado como un reconocimiento implícito de que resulta excesivo sancionar a un medio de comunicación por no informar sobre todos los asuntos de interés público. Además, las expresiones «obtener de forma ilegítima un beneficio propio, favorecer a una tercera persona y/o perjudicar a un tercero» resultan excesivamente abiertas e incumplen la necesaria concreción que deben tener las normas restrictivas de los derechos fundamentales.

A pesar del peso de las objeciones planteadas, la Corte Constitucional mantiene que todos los medios de comunicación sin excepción tienen el deber jurídico de informar sobre hechos de interés general y, en consecuencia, admite la posibilidad de sancionar a los medios que omitan informar sobre los mismos ${ }^{50}$. Según la Corte Constitucional, la restricción se justifica en la protección del

48 En este sentido, la Corte Interamericana reconoce la doble dimensión, individual y social o institucional, de las libertades de expresión e información y «ambas dimensiones poseen igual importancia y deben ser garantizadas en forma simultánea para dar efectividad total al derecho a la libertad de pensamiento y de expresión». Caso Vélez Restrepo y familia vs. Colombia, de 3 de septiembre de 2012, párr. 137 y ss.

49 Sobre el concepto de interés público o relevancia pública, a modo de ejemplo, entre otros, véanse De Domingo Pérez, T. (2001). ¿Conflictos entre derechos fundamentales?: un análisis desde las relaciones entre los derechos a la libre expresión e información y los derechos al honor y a la intimidad, Madrid, CEPC, págs. 199 y ss; Magdaleno Alegría, A. (2006). Los límites de las libertades de expresión e información, ob. cit., págs. 324 y ss; y MuÑoz LoRente, J. (1999). La libertad de información y el derecho al honor en el Código Penal de 1995, Valencia, Tirant lo Blanch, págs. 171 y ss.

50 Sentencia de la Corte Constitucional de Ecuador núm. 003-14-SIN-CC, de 14 de septiembre de 2014, págs. 97 y ss. 
derecho a recibir información de interés general consagrado en el art. 18.1 de la Constitución. En aplicación del principio de proporcionalidad, afirma que se trata de una medida idónea para alcanzar el citado fin, pues impone una sanción pecuniaria.

Discrepo de esta opinión de la Corte Constitucional, esencialmente por dos motivos. De un lado, la Corte no específica a través de qué procedimiento lógicodeductivo extrae un deber por el cual todos y cada uno de los medios de comunicación tienen que informar sobre todos los hechos de interés general. Se limita a sostener que «todas las personas tienen el derecho de recibir información de los acontecimientos de interés general y, por ende, los medios de comunicación no podrán omitir su difusión de manera deliberada y recurrente ${ }^{51}$ ». Una cosa es afirmar que los medios de comunicación tienen el derecho a difundir informaciones de interés general y que los ciudadanos puedan recibirlas sin interferencias externas, bien sea de los poderes públicos o de terceros; y otra cuestión bien distinta es establecer el deber de que todos los medios de comunicación informen sobre todos los hechos de interés público. De otro lado, la imposición del citado deber no supera el test de proporcionalidad ${ }^{52}$.

La sanción a los medios de comunicación por omitir informaciones de interés general no resulta una medida idónea, pues claramente existen medidas menos restrictivas para asegurar el derecho a la información de los ciudadanos. Si lo que se pretende es que todos los ciudadanos estén informados sobre asuntos de interés público, las omisiones de los medios de comunicación privados podrían ser colmadas por la acción de los medios públicos. En otras palabras, la LOC podría obligar a los medios de comunicación públicos a que informen sobre los asuntos de relevancia pública, e incluso establecer un catálogo de acontecimientos de interés general para la sociedad ${ }^{53}$. Los acontecimientos incluidos en el citado

\footnotetext{
51 Ibidem, pág. 99.

52 Sobre el principio de proporcionalidad en la doctrina y jurisprudencia alemana, entre otros, véanse Brage Camazano, J. (2004): Los límites a los derechos fundamentales, Madrid, Dykinson, págs. 215 y ss; Gavara De CARA, J.C. (1994). Derechos fundamentales y desarrollo legislativo: la garantía del contenido esencial de los derechos fundamentales en la Ley Fundamental de Bonn, Madrid, Centro de Estudios Políticos y Constitucionales, págs. 297 y ss; GonZÁlez Bielfuss, M. (2003). El principio de proporcionalidad en la jurisprudencia del Tribunal Constitucional, Cizur Menor, Aranzadi, págs. 54 y ss; Medina Guerrero M. (1996). La vinculación negativa del legislador a los derechos fundamentales, Aravaca, MacGraw-Hill, págs. 120 y ss; Alexy, R. (1997) Teoría de los derechos fundamentales, Madrid, Centro de Estudios constitucionales, 1997, págs. 111 y ss; y Winfried, K. (1998). «Prohibición de exceso y principio de proporcionalidad en Derecho alemán», Cuadernos de Derecho público, núm. 5, págs. 219 y ss.

53 A modo de ejemplo y en sentido cercano a la propuesta realizada supra, cabe citar el derogado art. 47 b) Ley española 7/2010, de 31 de marzo, General de la Comunicación Audiovisual
} 
catálogo deberán ser emitidos en abierto y para todo el país ${ }^{54}$. También se podrían implementar medidas que fomenten un mayor pluralismo de los medios de comunicación privados.

\subsection{La obligación de elaborar códigos deontológicos}

El art. 9 LOC establece que los medios de comunicación, independientemente de su titularidad (pública, privada o comunitaria) o modalidad (prensa escrita, radio, televisión, etc.) deben elaborar códigos deontológicos que regirán el desarrollo de su actividad. Concretamente, el art. 10 LOC establece que los medios de comunicación, de acuerdo a sus propias características, deberán incluir normas deontológicas destinadas a garantizar el respeto a la dignidad humana, la protección de determinados grupos de atención prioritaria, la observancia de normas concernientes al ejercicio profesional, etc. ${ }^{55}$.

Como se observa, no es el poder público quien impone una regulación concreta de la materia, tampoco se está ante un supuesto de autorregulación pura, esto es, no se deja a la exclusiva voluntad de los medios de comunicación el establecimiento de las normas deontológicas así como el método para garantizar su cumplimiento efectivo ${ }^{56}$, sino que más bien la LOC establece una autorregulación regulada o corregulación ${ }^{57}$. La LOC remite a la autorregulación de los

(en adelante, LGCA), que disponía que corresponde al Consejo Estatal de Medios Audiovisuales la función de aprobar el catálogo de acontecimientos de interés general para la sociedad.

54 Además, el citado listado sería un buen parámetro objetivo para controlar la actividad de los medios de comunicación públicos en su labor de informar sobre asuntos de interés general en sede parlamentaria.

55 El art. 8 del Reglamento de desarrollo de la LOC establece un plazo para su elaboración y la obligación de su publicación en la página web del medio de comunicación si la tuviere.

56 Sobre la autorregulación, entre otros, véase Esteve Pardo, J. (2002). Autorregulación. Génesis y efectos, Pamplona, Aranzadi.

57 Sobre las distintas técnicas de autorregulación, entre otros, véanse Gavara De CARA, J. C. (2013). «La autorregulación como mecanismo de autocontrol de los medios de comunicación: intervención pública y regulación interna» en Gavara De Cara, J. C. y De Miguel Bárcena J. (eds.) La autorregulación de los medios de comunicación como sistema de control, ob. cit., págs. 41 y ss; Darnuculleta I Gardela, M. M. (2005). Autorregulación y Derecho Público: la autorregulación regulada, Madrid, Marcial Pons.

En el ordenamiento jurídico español, el art. 12 LGCA ha previsto exclusivamente para el sector audiovisual, la corregulación. Concretamente ha reconocido el derecho a la autorregulación de los prestadores de servicios de comunicación audiovisual en los que se regularán los contenidos de la comunicación audiovisual y las reglas de diligencia profesional. La verificación de su eventual incumplimiento se atribuye a un órgano administrativo independiente (anteriormente el CEMA, hoy la CNMV). Se trata de una regulación que supone un grado de intervención de mucho menor 
medios de comunicación un amplísimo y heterogéneo número de temas como, por ejemplo, respetar la honra y reputación de las personas sobre las que se informa; abstenerse de emitir imágenes o menciones identificativas de niños y adolescentes como autores, testigos o víctimas de actos ilícitos; no utilizar en provecho propio información privilegiada; cuidar de que los titulares sean coherentes con el contenido de las noticias, etc. Valoro que la LOC remita a los códigos deontológicos el cumplimiento de los anteriores deberes, pues los medios de comunicación responden a distintas modalidades, tamaños y capacidades. Parece lógico tenerlo en cuanta a la hora de establecer el modo concreto de cumplir los deberes establecidos en la norma. Ahora bien, a diferencia de otras experiencias de derecho comparado, donde se establece que los propios medios establecen los mecanismos de control, la LOC reserva la supervisión de su cumplimiento a la Superintendencia de la Información y la Comunicación (en adelante, Supercom) que, en su caso, emitirá una amonestación escrita. La aludida amonestación supone una llamada de atención al medio sobre las prácticas que deben ser mejoradas o corregidas. Se trata de un mecanismo que pretende que los medios de comunicación reflexionen y traten de ejercer su labor con criterios de responsabilidad social. La amonestación supone una sanción de tipo moral, un reproche ante la opinión pública que trata de garantizar la calidad de la actividad de los medios de comunicación.

En conclusión, la obligatoriedad de que los medios de comunicación tengan que elaborar códigos deontológicos no plantea objeciones desde la perspectiva de la protección de las libertades de expresión e información.

\subsection{El linchamiento mediático}

Probablemente como consecuencia del enfrentamiento entre un amplio sector de los medios de comunicación privados y el Presidente de Ecuador, el art. 26 LOC ha incluido la sanción del linchamiento mediático, según el cual «queda prohibida la difusión de información que, de manera directa o a través de terceros, sea producida de forma concertada y publicada reiterativamente a través de uno o más medios de comunicación con el propósito de desprestigiar a una persona natural o jurídica o reducir su credibilidad pública». La LOC sanciona el linchamiento mediático mediante la obligación de realizar una disculpa pública por parte de las personas que produjeron y difundieron la infor-

intensidad que en el caso ecuatoriano. Sobre la regulación española, entre otros, véanse GAVARA De CARA, J. C. «La autorregulación como mecanismo de autocontrol de los medios de comunicación: intervención pública y regulación interna», ob. cit., 47 y ss. 
mación en el medio o medios de comunicación tantas veces como fue difundida. Se está ante precepto que resulta criticable por varios motivos:

En primer lugar, se trata de un precepto sumamente abierto e indeterminado y, por ende, difícilmente se adecúa al principio de tipicidad y a las exigencias de seguridad jurídica ${ }^{58}$. Resultan sumamente confusas las expresiones «de forma concertada» o «con el propósito de desprestigiar». ¿A qué se refiere con concertación?, ¿con quién se debe acordar?, ¿qué es tener el propósito de desprestigiar?, ¿basta con saber que la información que se difunde puede afectar al honor?, o ¿hay que tener una clara intencionalidad de que mediante la difusión de la información se desprestigie o se reduzca la credibilidad de alguien? Lo que sí deja claro es que el linchamiento mediático sólo prohíbe la difusión de informaciones, por tanto, sólo afecta a la libertad de información y no a la libertad de expresión.

En segundo lugar, el artículo 26 LOC no exige que el denunciante demuestre que las informaciones no sean veraces, tal y como prescribe el art. 18.1 de la Constitución, por lo que bastará que el sujeto que interpone la denuncia demuestre que la difusión de las informaciones afecta a su consideración social o credibilidad pública, además de la concertación y el propósito de desprestigiar, para que el medio sea sancionado ${ }^{59}$. Se trata de un precepto que potencialmente podría castigar el periodismo de investigación. Así, por ejemplo, puede imaginarse el caso de un consorcio de periodistas que realizan una investigación sobre la existencia de cuentas en paraísos fiscales de varios responsables públicos y, posteriormente, difunden la información de forma concertada y reiterada a través de sus respectivos medios y, además, con la clara intención de difundir un hecho

58 Sobre la cuestión, la Corte Interamericana considera que la definición legal de las restricciones a las libertades de expresión e información deben ser expresas y taxativas. Concretamente, considera que «la ley debe estar formulada con precisión suficiente para permitir a las personas regular su conducta, de manera de ser capaces de prever con un grado que sea razonable, de acuerdo a las circunstancias, las consecuencias que una acción determinada puede conllevar». Caso Fontevecchia y D’Amico vs. Argentina, de 29 de noviembre de 2011, párr. 93.

59 Resulta cuanto menos curioso que la Corte Constitucional admita la constitucionalidad del linchamiento mediático añadiendo un nuevo requisito a la norma para admitir su constitucionalidad. Concretamente, la Corte afirma que mediante el linchamiento mediático se «sancionarán a los medios de comunicación cuando difundan información de forma concertada y reiterada, sin observar las características previstas para dicha información en el artículo 18», esto es, cuando la información no sea veraz y, además, se difunda «con el propósito de vulnerar el derecho al honor y el buen nombre de las personas». El artículo 26 LOC sanciona la difusión de información con el propósito de desprestigiar o reducir la credibilidad pública de un sujeto, independientemente de si es veraz o no. Sentencia de la Corte Constitucional de Ecuador núm. 003-14-SIN-CC, de 14 de septiembre de 2014, pág. 137. 
cierto que saben que supondrá un desprestigio y pérdida de credibilidad de los responsables públicos.

En tercer lugar, también surgen serias dudas desde la perspectiva del fin constitucionalmente legítimo que fundamenta la restricción de la libertad de información. La Corte Constitucional considera que la restricción analizada se justifica en la protección del derecho al honor ${ }^{60}$. Se trata de una afirmación sólo parcialmente cierta, pues si bien es cierto que el derecho al honor protege la honra y la reputación, esto es, la consideración ajena. Sin embargo, este derecho no protege la credibilidad de las personas en la sociedad. Se trata de una cuestión distinta y, por tanto, al menos en lo referente a la intención de reducir la credibilidad pública, la restricción carece de un fin constitucionalmente protegido.

En cuarto lugar, la aplicación del linchamiento mediático resultará de enorme dificultad. Parece muy difícil demostrar en un procedimiento contradictorio la intencionalidad o propósito de desprestigiar a la hora de difundir la información por parte de los medios de comunicación. Lo mismo sucede a la hora de demostrar la concertación en la difusión de la información.

Por último, si ya existen regulaciones que protegen el derecho al honor de los ciudadanos, no se entiende la motivación del legislador a la hora de introducir este precepto. Se trata de una medida disuasoria que puede generar un efecto de desaliento en la labor de perro guardián de la prensa.

\subsection{Las autoridades de desarrollo normativo y control}

La LOC crea dos instituciones para desarrollar y aplicar sus disposiciones: de un lado, el Consejo de Regulación y de Desarrollo de la Información (en adelante, Cordicom). Y, de otro lado, la Supercom.

En derecho comparado existen instituciones similares y responden al esquema de administraciones independientes. Ahora bien, su ámbito de actuación se suele circunscribir a la radio y televisión, debido a su mayor influencia en el ámbito del entretenimiento y en la formación de la opinión pública, y normalmente una única institución desempeña las funciones de regulación y control ${ }^{61}$.

${ }^{60}$ Sentencia de la Corte Constitucional de Ecuador núm. 003-14-SIN-CC, de 14 de septiembre de 2014, pág. 134 y ss.

${ }^{61}$ Sobre las distintas autoridades audiovisuales, entre otros, véanse Autin, J-L. (2007). «El Consejo Superior del Audiovisual en Francia», Revista catalana de dret públic, núm. 34, págs. 83 y ss; Barata I Mir, J. (2006). Democracia y audiovisual, Madrid, Marcial Pons; Arenas Ramiro, M. (2015) «El régimen jurídico de los medios de comunicación en Alemania», ob. cit., págs. 539 y ss; Chinchilla, C. y Azpitarte, M. (2011). Estudios sobre la Ley General de Comunicación Audiovisual, Cizur Menor, Aranzadi; Gavara De CARA, J. C. (2013). Las autoridades independientes de 
Se trata de instituciones independientes, tanto del poder público como de los intereses económicos ${ }^{62}$, y especializadas, que desarrollan varias actividades, entre las que destacan las siguientes ${ }^{63}$ : a) Controlar que la programación de todas las radios y televisiones públicas y privadas respeten una serie de deberes que varían según el ordenamiento jurídico del concreto país. A modo de ejemplo, se aludirá a que las citadas autoridades velarán por el respeto de los derechos fundamentales, siendo los que plantean mayor número de conflictos los derechos al honor, intimidad personal y familiar, propia imagen y la presunción de inocencia; la protección de los menores (que su imagen y voz no sean utilizadas de manera reconocible, prohibición de la difusión de su nombre, imagen u otros datos que permitan su identificación en el contexto de la investigación y enjuiciamiento de los delitos) etc.; b) Autorizar y distribuir las licencias de emisión de radio y televisión tras el correspondiente concurso público por tiempo determinado, así como requerir a los concesionarios el cumplimiento de sus obligaciones; c) Garantizar un plural ejercicio del derecho de información; d) Asegurar el pluralismo externo de los medios de comunicación actuando contra las prácticas restrictivas de la competencia y la concentración de los medios de comunicación ${ }^{64}$; e) Designar los órganos de dirección de los medios de comunicación públicos (director, miembros del consejo de administración, etc.).

Para el desarrollo de sus funciones suelen tener reconocida la capacidad reglamentaria y de sanción. También ejercen a modo de institución de influencia, pues suelen sugerir a los poderes públicos normativas adecuadas a las nuevas necesidades sociales o indicar prácticas que supongan la mejora de la actividad de los medios de comunicación.

control de los medios de comunicación audiovisual, Barcelona, Bosch; Belando Garín, B. y MONTIEL RoIG, G. (Coords.) (2011). Contenidos y mercado en la regulación de la Comunicación audiovisual, Valencia, Tirant lo Blanch; y Rallo Lombarte, A. (2000). «La garantía del pluralismo informativo en Francia. El Conseil Supérieur de L'audiovisuel», ob. cit., págs. 93 y ss.

${ }_{62}$ En referencia a los citados órganos, resulta de interés la lectura de la Declaración Conjunta sobre Desafíos a la Libertad de Expresión en el Nuevo Siglo, aprobada el 20 de noviembre de 2001.

${ }^{63}$ Se trata de instituciones que tienen cada vez mayores dificultades o lagunas en su labor de regulación y control debido a las importantes y rápidas transformación de los formatos de transmisión de la información y, sobre todo, como consecuencia de las nuevas posibilidades que genera Internet. De hecho, la mundialización del fenómeno de la comunicación pública aconseja que sean autoridades supranacionales, regionales o mundiales, las encargadas de intervenir en esta materia.

${ }^{64}$ Se trata de evitar la formación de una opinión pública dominante a través de medidas anticoncentración. Los sistemas más efectivos de medidas anticoncentración como el alemán se basan en en las cuotas de audiencia. 
Como se dijo, la LOC optó por crear dos instituciones diferentes, una de regulación y otra de control:

La primera, por sus siglas Cordicom, regula, entre otras cuestiones, la clasificación de contenidos y franjas horarias; los procedimientos administrativos para que los ciudadanos presenten reclamaciones sobre el ejercicio de los derechos de comunicación $^{65}$; los mecanismos que permitan la variedad de la programación, con orientación hacia programas educacionales y/o culturales; etc. También desarrolla otras importantes atribuciones al objeto de garantizar el pluralismo externo de los medios como elaborar informes vinculantes para la adjudicación o autorización de concesiones de frecuencias del espectro radioeléctrico. Asimismo le corresponde determinar mediante resolución razonada si un determinado contenido comunicativo es discriminatorio ${ }^{66}$. Para el desempeño de sus actividades, el Cordicom cuenta con la ayuda de un órgano consultivo compuesto por miembros provenientes de los sectores afectados por los contenidos de la LOC (realizadores audiovisuales, comunicadores sociales, etc.)

La segunda, en sus siglas Supercom, es un «organismo técnico de vigilancia, auditoría, intervención y control, con capacidad sancionatoria» sobre todos los medios de comunicación. La Supercom tiene, entre otras, las siguientes competencias: a) fiscalizar, supervisar y ordenar el cumplimiento de las disposiciones legales y reglamentarias sobre los derechos de comunicación; b) atender, investigar y resolver las denuncias formulados por personas físicas o jurídicas en materia de derechos de comunicación; c) requerir a los ciudadanos, instituciones y actores relacionados con la comunicación, la información sobre sí mismos que fuere necesaria para el cumplimiento de sus atribuciones, etc.

Son varias las críticas que merece la regulación de estas instituciones, entre las que destacan las siguientes:

65 Las concretas normas de desarrollo emitidas por el citado órgano se pueden consultar a través del siguiente enlace: http://www.cordicom.gob.ec/reglamentos-cordicom/ (fecha de consulta: 17/04/2015).

66 Concretamente, según el art. 63 LOC, para que un determinado contenido sea calificado como discriminatorio, se debe demostrar la concurrencia de los siguientes elementos: 1. Que el contenido difundido denote algún tipo concreto de distinción, exclusión o restricción; 2. Que tal distinción, exclusión o restricción esté basada en una o varias de las razones establecidas en el art. 61 de esta Ley; y, 3. Que tal distinción, exclusión o restricción tenga por objeto o resultado menoscabar o anular el reconocimiento o goce de los derechos humanos garantizados en la Constitución y en los instrumentos internacionales; o que los contenidos difundidos constituyan apología de la discriminación o inciten a la realización de prácticas o actos violentos basados en algún tipo de discriminación. 
En primer lugar, el sistema de elección de los órganos de regulación y control examinados no garantiza su independencia respecto de la autoridad gubernamental o, cuanto menos, no responde a un consenso amplio que tenga en cuenta el pluralismo político y social existente en el país ${ }^{67}$. El caso más claro es la Supercom, pues se elige por el Consejo de Participación ciudadana y control social entre una terna de candidatos a propuesta del Presidente de la República ${ }^{68}$. En referencia al Cordicom no se asegura que la selección de sus miembros se realice mediante consenso, ni la representación del pluralismo político y social. Aún siendo consciente de las críticas que han cosechado las resoluciones de las autoridades independientes de control, si acudimos al derecho comparado se pueden extraer algunas ideas para mejorar la LOC. Si la premisa consiste en asegurar el pluralismo e independencia de los medios de comunicación, se debe garantizar el pluralismo interno en la composición de las aludidas autoridades y, en consecuencia, se deben contemplar entre otras, las siguientes medidas: que en el sistema de designación de sus miembros se requieran mayorías cualificadas; que puedan participar en su elección las distintas corrientes de la sociedad (asociaciones, entidades religiosas, etc); requerir requisitos de capacitación profesional de sus miembros o regular la composición plural del órgano.

En segundo lugar, tras el estudio de las primeras resoluciones emitidas por la Supercom, se observa que a la hora de razonar sus resoluciones apenas acude a la fundamentación propia de los derechos. Se trata de una cuestión obligada, pues tal y como establece el art. 11 de la Constitución, «los derechos y garantías establecidos en la Constitución y en los instrumentos internacionales de derechos

${ }^{67} \mathrm{El}$ art. 48 LOC establece que el Cordicom tiene la siguiente composición: «1. Un representante de la Función Ejecutiva, quien lo presidirá. 2. Un representante de los Consejos Nacionales de Igualdad. 3. Un representante del Consejo de Participación Ciudadana y Control Social. 4. Un representante de los Gobiernos Autónomos Descentralizados. 5. Un representante del Defensor del Pueblo».

En el caso de la Supercom, según el art. 55 LOC, «será nombrado por el consejo de participación ciudadana y control social de una terna que enviará la Presidenta o Presidente de la República de conformidad con lo establecido en la Constitución».

${ }^{68}$ En el caso español, los miembros del extinto CEMA debían ser elegidos por mayoría de tres quintos (art. 49.1 LGCA) del Congreso de los Diputados. Si transcurridos dos meses no se hubiera elegido, se designará mediante mayoría absoluta. Mediante el alto de consenso exigido se trataba de garantizar la calidad técnica de los seleccionados, además de su neutralidad e imparcialidad. Ahora bien, estamos ante un objetivo condicionado a la cultura política del país, en la medida de que el pacto de cuotas entre los partidos políticos mayoritarios y la designación de miembros teniendo en cuenta la afinidad política y no técnica pone en cuestión la necesaria independencia de estos órganos de reglamentación y control. No obstante lo dicho, la exigencia de amplias mayorías por lo menos asegura que los miembros de estos órganos respondan a la pluralidad política del país. 
humanos serán de directa e inmediata aplicación por y ante cualquier servidora o servidor público, administrativo o judicial, de oficio o a petición de parte». Entre otras, se han detectado las siguientes omisiones: a) No se aplica la doctrina de la posición preponderante de la libertad de expresión derivada de la función que desempeña en el sistema democrático mantenida por la Corte Interamerica$\mathrm{na}^{69}$. b) No acude al método de ponderación casuística para resolver los concretos conflictos entre las libertades de expresión e información y otros derechos fundamentales. En muchos de los casos analizados se limita a la mera subsunción de la acción en la sanción establecida en la norma. La ausencia de ponderación a la hora de resolver conflictos entre derechos fundamentales implica su vulneración. c) En muchas ocasiones sanciona a los medios audiovisuales por no diferenciar entre hechos y opiniones, pero no aporta criterios para realizar la citada separación en cada noticia en concreto. d) Utiliza el diccionario de la RAE o acude a la doctrina científica para delimitar conceptos como honra y reputación, cuando debería acudir a la jurisprudencia de la Corte Interamericana. e) No tiene en cuenta que en el caso de la crítica dirigida a las personas que ocupan puestos de responsabilidad política o pública, los límites admisibles son mayores $^{70}$, esto es, el umbral de tolerancia a la crítica es mayor que en otros casos ${ }^{71}$. Dicho en otras palabras, cuando se ejerce la libertad de expresión en referencia a representantes públicos, aquélla goza de una especial protección ${ }^{72}$.

En tercer lugar, a diferencia de las experiencias en derecho comparado, las autoridades de regulación y control de Ecuador carecen de competencias e instrumentos específicos para garantizar el pluralismo, independencia e imparcialidad del sector público audiovisual ${ }^{73}$. La configuración de las autoridades de

69 Ahora bien, conviene aclarar que la afirmación de que la libertad de expresión en sentido amplio es preponderante sólo y en la medida de que desempeñe su función social, esto es, su papel en el funcionamiento del sistema democrático. Sólo resultarán legítimas las injerencias en otros derechos o bienes constitucionalmente protegidos que guarden congruencia y en la medida de lo estrictamente necesario para permitir la formación de la opinión pública. A modo de ejemplo, véase caso Kimel Vs. Argentina, de 2 de mayo de 2008, párrs. 87 y ss.

${ }^{70}$ A modo de ejemplo, véase Resolución de la Supercom núm. 25-2014-INPS-DNJRD.

${ }^{71}$ Como afirma la Corte Interamericana, «en la arena del debate sobre temas de alto interés público, no sólo se protege la emisión de expresiones inofensivas o bien recibidas por la opinión pública, sino también la de aquellas que chocan, irritan o inquietan a los funcionarios públicos o a un sector cualquiera de la población». Caso Kimel vs. Argentina, de 2 de mayo de 2008, párr. 88.

72 Concretamente, la Corte Interamericana mantiene que «las expresiones concernientes a la idoneidad de una persona para el desempeño de un cargo público o a los actos realizados por funcionarios públicos en el desempeño de sus labores gozan de mayor protección, de manera tal que se propicie el debate democrático». Ibidem, párr. 86.

73 A modo de ejemplo, véase art. 45 LGCA española (versión 2010). 
regulación y control está diseñada casi en exclusiva respecto a la actividad de los medios de comunicación privados. Si bien la LOC establece algunos objetivos genéricos para los medios de comunicación públicos ${ }^{74}$, omite instrumentos para garantizar su pluralismo interno.

Por último, en cuanto a las sanciones que puede imponer la Supercom, van desde las simples amonestaciones escritas donde se previene a los medios de que deben mejorar y corregir sus prácticas, a la imposición de determinados deberes como, por ejemplo, la de rectificar públicamente la noticia o la imposición de multas. En el momento de elaboración de este estudio, se constata el importante número amonestaciones, rectificaciones y sanciones impuestas, en su gran mayoría sobre los medios de comunicación privados.

\section{4. ¿SE PUEDEN CONSEGUIR IDÉNTICOS OBJETIVOS MEDIANTE OTROS MEDIOS?}

A pesar de que la LOC establece regulaciones positivas al objeto de garantizar el ejercicio efectivo de las libertades de comunicación y fomentar el pluralismo como, por ejemplo, la promoción de los medios de comunicación comunitarios $^{75}$, el acceso en condiciones de igualdad al espacio radioeléctrico, la prohibición de concentración de medios de comunicación, etc., lo cierto es que contiene varias regulaciones que resultan incompatibles con los estándares al uso en materia de libertad de expresión e información, que, en consecuencia, deben ser rectificados.

También es susceptible de crítica que la norma haya omitido instrumentos que resultan más apropiados y proporcionados para el cumplimiento de los fines pretendidos. Se trata de omisiones que hacen cuanto menos dudar de que la norma tenga una sincera voluntad de garantizar el pluralismo y el ejercicio efectivo de las libertades de comunicación, entre otros, por los siguientes motivos:

En primer lugar, si el objetivo de la norma consiste en garantizar el pluralismo y la participación ciudadana, parece claro que debería haber regulado en referencia a los medios de comunicación públicos un deber de contribuir a la formación de una opinión pública plural y atender a aquellos ciudadanos o gru-

74 Art. 80 LOC.

75 A pesar de regulación de los medios de comunicación comunitarios, lo cierto es que su implantación es todavía minoritaria. Según el Observatorio latinoamericano de regulación, medios y convergencia, tras dos años de vigencia de la LOC, sólo se han otorgado licencias provisionales para 14 nacionalidades indígenas, mientras que los medios privados conservan alrededor del 85 por ciento de la propiedad del radioespectro. 
pos sociales que no son destinatarios de la programación mayoritaria ${ }^{76}$. En referencia a la información política sería interesante estudiar incluir en la LOC la regulación de tiempos de palabra para las personalidades políticas. A modo de ejemplo, en el ordenamiento jurídico francés rige la regla de los tres tercios que, de manera sintética, consiste en el reparto del tiempo de palabra de forma igual, por tercios, entre el Gobierno, la mayoría parlamentaria y la oposición parlamentaria ${ }^{77}$.

En segundo lugar, omite realizar cualquier regulación al objeto de garantizar el acceso de los grupos políticos y sociales más significativos a tiempos de antena en los medios de comunicación públicos ${ }^{78}$. Si lo que se pretende es garantizar una formación de la opinión pública plural, se debe garantizar su acceso efectivo a los medios de comunicación. Por ello, la LOC debería regular, entre otras cuestiones, los criterios específicos para determinar cuáles son los grupos sociales y políticos más significativos de la sociedad, cómo se llevará a cabo la distribución de tiempos de antena en la programación de los medios de comunicación públicos, etc. ${ }^{79}$.

${ }^{76}$ En el ordenamiento jurídico español fundamentalmente son tres las normas que hacen referencia a la regulación de los medios de comunicación públicos: en primer lugar, la Ley 17/2006, de 5 de junio, de la radio y la televisión de titularidad estatal; la ley 8/2009, de 28 de agosto, de Financiación de la Corporación Pública de Radio y Televisión Española y la Ley 7/2010, de 31 de marzo, General de la Comunicación Audiovisual (en adelante, LGCA). Concretamente, el art. 40 LGCA califica el servicio público de la comunicación audiovisual como un servicio esencial de interés económico general que «tiene como misión difundir contenidos que fomenten los principios y valores constitucionales, contribuir a la formación de una opinión pública plural, dar a conocer la diversidad cultural y lingüística de España (...) Asimismo (...) atenderán a aquellos ciudadanos y grupos sociales que no sean destinatarios de la programación mayoritaria»

77 En referencia al control efectuado por el Consejo audiovisual francés de los medios de comunicación públicos y privados en cuanto al pluralismo, equilibrio e igualdad durante la campaña electoral cabe destacarse que además del tiempo de palabra de los candidatos o de sus apoyos, el citado consejo controla los equilibrios en los tiempos de antena. Esto es, vigila el equilibrio en la presentación en antena, esto es, el trato otorgado a las actividades públicas del candidato, los balances, comentarios y presentaciones a los que da lugar la elección. Mientras que el tiempo de palabra mide la expresión efectiva del candidato, el tiempo de antena afectará al conjunto del trato editorial sobre un candidato. Véase Rallo Lombarte, A. (2000). «La garantía del pluralismo informativo en Francia. El Conseil Supérieur de L'audiovisuel», ob. cit., págs. 132 y ss.

${ }^{78}$ En este sentido, la Corte Interamericana, tras destacar que «las voces de oposición resultan imprescindibles para una sociedad democrática, sin las cuales no es posible el logro de acuerdos que atiendan a las diferentes visiones que prevalecen en una sociedad», mantuvo que «la participación efectiva de personas, grupos y organizaciones y partidos políticos de oposición en una sociedad democrática debe ser garantizada por los Estados, mediante normativas y prácticas adecuadas que posibiliten su acceso real y efectivo a los diferentes espacios deliberativos en términos igualitarios». Caso Manuel Cepeda Vargas vs. Colombia, de 26 de mayo de 2010, párr. 173.

79 Sobre el acceso a los medios de comunicación públicos en el ordenamiento jurídico español, entre otros, Magdaleno Alegría, A. (2006). «El derecho de acceso a los medios de comunicación 
Por el contrario, cuestión que abunda en la incongruencia de norma, la LOC sí regula la facultad gubernamental de emitir mensajes obligatorios o cadenas presidenciales donde se obliga a los medios de comunicación audiovisuales a «encadenarse» a la señal oficial para difundir la opinión oficial en los medios de comunicación privados ${ }^{80}$. La Relatoría especial para la libertad de expresión considera que la utilización de este recurso debe ser muy restringida ${ }^{81}$. Para evitar el ejercicio abusivo de la aludida facultad sería de interés reconocer un derecho de réplica a las comunicaciones del gobierno. Se trataría de reconocer un derecho de réplica a las formaciones políticas que ejercen la oposición y que ostentan representación parlamentaria, disponiendo de un tiempo de antena equivalente de acuerdo a su representación en la Asamblea y en condiciones de programación equivalentes ${ }^{82}$.

En tercer lugar, si se quiere garantizar el derecho de los ciudadanos a recibir informaciones de interés público y, de esta manera, no dejar en manos de los medios de comunicación privados determinar qué asuntos son de interés público, se deberían subsanar sus omisiones mediante la actuación de los medios de

públicos de los grupos sociales y políticos significativos en el Estado social y democrático de Derecho», Teoría y Realidad Constitucional, págs. 223 y ss.

En el ordenamiento jurídico francés corresponde al Conseil Superior de l'Audiovisuel garantizar el pluralismo político en la programación de televisión y radio para lo que, entre otras medidas, hará cumplir unas cuotas de pantalla para el Presidente de la República, el Gobierno y la oposición. El tiempo se acuerda cada año para las distintas formaciones políticas representadas en el Senado o en la Asamblea Nacional. Asimismo también se establecen tiempos de antena para las organizaciones sindicales y profesionales representativas a nivel nacional. El citado Conseil Superior de l'Audiovisuel ha regulado, entre otras cuestiones: qué radios y televisiones públicas deben realizar las emisiones; horario; la atribución global y concreta de los tiempos de emisión, etc. Sobre el tema, entre otros, véase ROIG, A. «La autoridad independiente de control de los medios de comunicación audiovisual en Francia», ob. cit., pág. 274 y ss; Rallo Lombarte, A. (2000). «La garantía del pluralismo informativo en Francia. El Conseil Supérieur de L'audiovisuel», ob. cit., págs. 125 y ss.

80 Art. 74 LOC.

${ }^{81}$ Así, afirma que: «La información que los gobiernos transmiten a la ciudadanía a través de las cadenas presidenciales debe ser aquella estrictamente necesaria para atender necesidades urgentes de información en materias de claro y genuino interés público, y durante el tiempo estrictamente necesario para trasmitir dicha información». Sobre los casos concretos de su utilización, véanse los Informes de la Relatoría especial para la libertad de expresión de 2011 y 2014, accesibles a través de los siguientes enlaces: http://www.oas.org/es/cidh/expresion/docs/informes/anuales $/ 2012 \% 2003 \% 2021 \% 20$ Informe\%20Anual\%20RELE\%202011\%20impresion.pdf http:// www.oas.org/es/cidh/expresion/docs/informes/anuales/Informe\%20Anual\%202014.pdf (fecha de consulta: $14 / 04 / 15)$

${ }^{82}$ Sobre la regulación del derecho de réplica a los mensajes del Gobierno en el ordenamiento jurídico francés, véase RALlo LombarTe, A. (2000). «La garantía del pluralismo informativo en Francia. El Conseil Supérieur de L'audiovisuel», ob. cit., págs. 123 y ss. 
comunicación públicos. A tal objeto resultaría conveniente el establecimiento de un catálogo de asuntos de interés general o, en su caso, regular los criterios para su determinación por parte de los organismos de regulación y control. Al objeto de contribuir a una comunicación audiovisual plural, los medios de comunicación públicos deben incluir una programación que incluya distintos géneros y atienda a los diversos sectores de la sociedad, especialmente a aquellos que no son destinatarios de la programación mayoritaria ${ }^{83}$.

$\mathrm{Y}$, por último, a fin de garantizar el pluralismo interno de los medios de comunicación públicos y, por ende, asegurar su independencia del gobierno y neutralidad política, se debe regular que en la composición de los órganos de dirección tiene que estar presente la pluralidad de la sociedad, así como establecer mecanismos para que la elección de su máximo responsable goce de un amplio consenso ${ }^{84}$. Asimismo, la LOC debería incluir una regulación específica que permita canalizar la fiscalización política del cumplimiento de su misión como servicio de titularidad pública ${ }^{85}$.

${ }^{83}$ En este sentido, arts. 4 y 40 LGCA.

${ }^{84} \mathrm{El}$ art. 78 LOC se limita a afirmar que gozarán de autonomía editorial, sin especificar su sistema de garantías y, además, contempla deberán tener un Consejo Editorial y consejo ciudadano, pero omite cualquier alusión a su pluralismo interno e independencia.

Uno de los modelos más garantistas de la independencia y pluralismo interno en los medios de comunicación públicos es el modelo alemán. En concreto, la radiotelevisión pública se ofrece a través de las Instituciones de Radiotelevisión que son instituciones de Derecho público que gozan de autonomía funcional. Las citadas Instituciones de Radiotelevisión se componen, esencialmente, de tres órganos: el consejo de radiotelevisión, el consejo de administración y el intendente. El consejo de radiotelevisión es el máximo representante de la institución, entre otras funciones, participar en la elección del Consejo de Administración, establece las directrices de su programación y sólo o de forma conjunta con el Consejo de Administración, elige el intendente. En su composición, esto es lo que interesa destacar, debe garantizarse la representación de todas las organizaciones, confesiones religiosas, grupos e instituciones correspondientes al Land. Su composición debe reflejar el pluralismo existente en la sociedad y, de esta manera, se pretende asegurar la prestación del pluralismo esencial de la radiotelevisión y la libertad en el proceso de formación de la formación de la opinión pública. También se incluyen previsiones normativas para asegurar el pluralismo del consejo de administración, que ejerce funciones de dirección económica y de control de la programación.

Sobre la Comisión de vigilancia de la radiotelevisión pública italiana (RAI) y la teoría y realidad del nombramiento del Consejo de Administración y presidente del citado ente, véase PAvANI, G. (2015). «El régimen de los medios de comunicación en Italia. El sistema de radio y televisión: ¿Una anomalía en el contexto comparado?», ob. cit., 482 y ss.

${ }^{85}$ Los arts. 82 LOC y 35 de su reglamento de desarrollo remiten genéricamente a que los Consejos de ciudadanos de los medios de comunicación públicos, elegidos de acuerdo a la ley de participación y control social, velarán por que los contenidos difundidos promuevan y respeten el ejercicio de los derechos de comunicación y que contribuyan a mejorar la oferta de contenidos. Sin 
Title:

THE ORGANIC LAW OF COMMUNICATION OF ECUADOR, IS IT A REAL MOVE FORWARD IN THE EFFECTIVE EXERCISE OF THE FREEDOM OF SPEECH AND INFORMATION AND THE CIVIC PARTICIPATION?

\section{Summary:}

Introduction. 1. The constitutional Ecuadorian and Interamerican recognition of freedom of speech and information. 2. Democratic approach to freedom of speech and information as a premise to the Organic Law of Communication. 3. Study of the most controversial aspects of the Organic Law of Communication. 3.1 The dubious qualification of media as public services. 3.2 Inappropriate use of the concept of preventive censorship and obligation of reporting about affairs of public interest. 3.3 Obligation of creating a code of ethics. 3.4 Media lynching. 3.5 Independent authorities of regulatory development and control. 4. Could similar objectives be achieved by less restrictive methods?

\section{Resumen:}

Con el objetivo de garantizar el efectivo ejercicio de las libertades de expresión e información y fomentar la participación ciudadana, la Asamblea Nacional de Ecuador aprobó la Ley Orgánica de Comunicación en 2013. La citada norma ha sido criticada, entre otros, por la Relatoría especial para la libertad de expresión de la Comisión Interamericana de Derechos Humanos, organizaciones nacionales e internacionales de periodistas y la mayoría de los medios de comunicación privados de Ecuador. Entre otras cuestiones, han censurado que la citada norma califica como servicio público la actividad de todos los medios de comunicación independientemente de su titularidad o modalidad, que se castigue la censura por omisión o la nula independencia de los organismos de control de la actividad de los medios de comunicación.

El estudio analiza si la Ley Orgánica de comunicación supone una auténtica democratización del ejercicio de las libertades de expresión e información y un fortalecimiento de la participación ciudadana o si, por el contrario, contiene regulaciones que posibilitan la influencia

embargo, considero que no se trata de un mecanismo efectivo. Probablemente son muchos más efectivos los mecanismos de control político llevados a cabo por los representantes del pueblo. Así, el art. 20.3 de la Constitución española prescribe que «la ley regulará la organización y el control parlamentario de los medios de comunicación social dependientes del Estado». 
gubernamental sobre los contenidos comunicativos de los mass media $\mathrm{y}$, por ende, hacen dudar de la sinceridad del legislador ecuatoriano.

\begin{abstract}
:
The National Assembly of Ecuador approved the Organic Law of Communication on 2013 aiming to guarantee the effective exercise of the freedom of speech and freedom of information as well as to encourage civic participation. This law has been criticized by several organizations such as the Special Reportership for the freedom of speech of the Interamerican Commission for the Human Rights, national and international journalists' organizations and most of the private media of Ecuador. Some of the issues that have been criticized are that the mentioned law qualifies as public service the activity of every media independent on their ownership or format, punishes the omission censorship and the nonexistent neutrality of the authorities in charge of the control of the activity of the media as well.

This study analyses whether the Organic Law of Communication poses a real democratization of the exercise of the freedom of speech and information and a strengthening of the civic participation or if, on the contrary, includes regulations that enable the governmental control of private media and, therefore, casts doubts on the sincerity of the Ecuadorian legislator.
\end{abstract}

Palabras clave:

Ecuador, libertad de expresión, Ley Orgánica de Comunicación, Censura por omisión, linchamiento mediático.

\title{
Keywords:
}

Ecuador, freedom of speech, Organic Law of Communication, omission censorship, media lynching. 